\title{
An Analysis of Seedbed Designs for Forage Crop Production Under Arid Conditions
}

Tim A. Wiggins

Department of Agricultural Mechanization

\section{Carl E. Olson}

Department of Agricultural Economics \& Rural Studies

College of Agriculture, Sultan Qaboos University

P.O. Box 34 Al-Khod 123

Muscat, Sultanate of Oman

\begin{abstract}
A significant increase in the demand for forage crops has occurred in the Sultanate of Oman due to an escalating demand for meat and milk in the country. Research relative to effective tillage systems for seedbed preparation for increasing the production of forage crops is requisite to meet the rising demand for livestock products. This paper discusses the effects of the flat-bed, furrow, and ridge seedbed designs on sorghum production under the harsh arid environment of the Sultanate. The ridge design yielded significantly higher results in the categories of root length, plant height, fresh-weight and dry-weight compared with the furrow and flat-bed designs. Sorghum samples from the sorghum planted in the furrow design had significantly more leaves than samples planted in the flat-bed design. The flat-bed design yielded significantly higher results compared with the furrow design relative to the number of plant tillers, fresh-weight and dry-weight. The value of the additional sorghum fodder produced from the ridged seedbed is considerably greater than the additional costs of the seedbed preparation.
\end{abstract}

Key words: Arid, Economic analysis, Forage, Seedbed design, Tillage.

\section{INTRODUCTION:}

The need for greater food supplies continues to escalate in many of the developing countries at the same time that land and water resources are appoaching over-use (Baruchin et. al. 1992, Sahn 1989, Seavoy 1989). This is particularly true on the Arabian peninsula due to the growing demand for milk and meat producing animals for 
consumption by the growing population (Alyaeesh et. al. 1988). The result has been a significant increase in the demand for forage crops, and an immediate need for research relative to effective forage-crop production systems in a harsh arid-environment.

The Sultanate's climate in the primary farming regions is characterized by high humidity, high solar irradiance, high salinity, and extremely high growing-season temperature. The availability of potable water for irrigation is the most important limiting factor for crop production. The encroachment of salt-water and a declining water table are serious problems which threaten agricultural production with the Sultanate. Efficient utilization of the important and limited waterresource requires research on forage crops which have a high wateruse-efficiency and are adaptable to the arid environment found on the Arabian peninsula (Alyaeesh et. al. 1988).

The primary forage crops grown in the Sultanate are alfalfa and rhodesgrass, with small amounts of sorghum, Sudan grass and maize are produced to a lesser degree. As a supplement to these forage crops, protein-rich animal feeds are imported at high cost by the government and are subsidized to the farmers. Research on alternative forage-grass production is needed to reduce the importation of expensive feed material and to boost the rate of forage production to meet the rising demand. Sorghum appears to be a responsive alternative to be grown under arid conditions for the production of forage materials (Jones 1987, Foale and Myers 1980).

As a consequence of supply and demand, the farming methods of the farmer in the Sultanate are gradually changing, moving from traditional low-productivity farming to modern high-potential productivity farming subject to technological limitations (Younis, 1986). Farmers in the Sultanate are not, however, limited by the lack of technologically-advanced machinery, but by the lack of knowledge relative to the most effective use of machinery for crop production. Successful production of an alien crop requires not only a thorough understanding of the plant's requirements and responsive characteristics, but a basic knowledge of proven tillage techniques relative to the crop's specific production dynamics.

Regardless of the crop type, the primary objectives of pre-plant and planting tillage operations are to improve seedbed environment, and to provide a known pattern of favorable and unfavorable locations (Klepper et. al. 1989). When water-supply is limited, optimum crop production requires a soil condition favorable for water infiltration, seed germination, plant emergence, early growth, and root development (Benjamin et. al. 1992, Wannapee 1982). 
The desired effect of any tillage operation performed in the preparation of the seedbed is to improve the soil condition relative to changes in the soil, air and water distribution, resisitance to the penetration of roots, and erosion and weed control characteristics. The degree to which the interactions between the above parameters are combined to achieve good crop growth and yield at acceptable cost in terms of inputs and soil deterioration determines the overall success of the tillage operation (Anazodo et. al. 1991).

The success of a crop often depends not only on the preplant tillage techniques utilized, but to a greater extent on the seedbed environment itself, as created by weather history, previous tillage, and planting and tillage equipment at seeding. Seedbeds designs have a marked effect on microclimate both above and below the soil surface (Dainello et. al. 1982). Factors such as soil temperature, moisture, compaction, concentrations of chemicals and aeration can independently or interactively cause harsh seedbeds and result in poor plant stands. A harsh seedbed environment may kill the seedling or stress it severely enough to limit the plant's productive potential, negating any benefit of the tillage system employed. Plant stress, whether caused by poor seedbed quality or imposed by the seedbed, delays emergence, slows the rate of emergence and decreases the final stand counts (Klepper et. al. 1989].

The design of the seedbed and the effect of the tillage implements utilized may have more influence on the seedbed environment than any of the preplant tillage systems employed. Pidgeon (1982) and Benjamin et. al. (1992) concluded that plants require a continuous pore system, adequate for drainage and root development, and that soil should have a structure that does not collapse from implement weight or from natural processes. Research concerning the effects of seedbed-tillage design on the production of forage crops under arid conditions remains varied and inconclusive (Aina 1979, Hina 1982, Lal 1973, Kowal and Stockinger 1973, and Ezendinma, 1964).

The combination of these factors make research mandatory if efficient forage-crop production systems are to be found which will meet the growing agricultural demands on the Arabian peninsula. In response to those needs, this study was undertaken to compare the effects of three different seedbed designs (ridge, furrow and flat-bed) on the production of sorghum under arid conditions in the Sultanate of Oman. The study also includes comparisons of the costs of the three seedbeds to determine if the value of the additional sorghum produced is greater than the additional costs associated with the altemative seedbed proposed. The flat-bed system of planting, which requires the 
least work in terms of seedbed preparation is used as the bench-mark system.

\section{MATERIALS AND METHODS}

The research was conducted during the 1991 and 1997 growing season at the Sultan Qaboos University research farm near Muscat, Sultanate of Oman. The soil type in the research plats is sandy loam, which is the typical soil type in much of the principal farming area in Oman. Primary tillage was accomplished by disking and harrowing prior to the construction of the three types of seedbeds. Each of the seedbeds; the flat-bed, the furrow and ridge design; were $4 \times 12$ meters in size. Sorghum was mechanically planted in each of the three seedbed designs at the same seeding rate per square meter. Water (by sprinkler irrigation) fertilizer and insecticides were applied at the same rate for all three seedbeds at the same time. Weeding was done by hand in order to leave the seedbed designs undisturbed.

At the end of the growing period, ten random samples were taken from each treatment area, a total of twenty samples for each seedbed design for the two growing seasons, a total of sixty samples from the three different areas. Data on plant fresh-weight (Bhatt \& Evans 1977), plant dry-weight (Lowe and Ries 1972) were recorded. The NewmanKeuls Multiple Comparisons test and analysis of variance were utilized for statistical analysis of the data.

\section{RESULTS AND DISCUSSION}

The mean root-length of the sample sorghum plants is shown in Figure 1 for the three treatment methods. A significant difference in root length was indicated between the samples from the ridge treatment group and those from the other two treatments. The statistical results are shown in Appendix Table 1. The results of the analysis indicate that the roots of the sorghum sampled from the ridge treatment area had a mean length in excess of $25 \%$ longer than those in the flat-bed and furrow areas. See Figure 1.

The results of the data for mean plant height parallel that of mean root length (Figure 2). A significant difference was again found between sorghum plants sampled from the ridge treatment with those from the furrow and flat-bed treatments. See Appendix Table 1 for the statistical analysis. Figure 2 illustrates that sorghum plants sampled from the ridge treatment grew significantly taller (greater than 20\%) than those from the flat-bed or furrow areas. There was no significant difference in plant height between the sorghum plants sampled from the flat-bed and furrow treatments. 


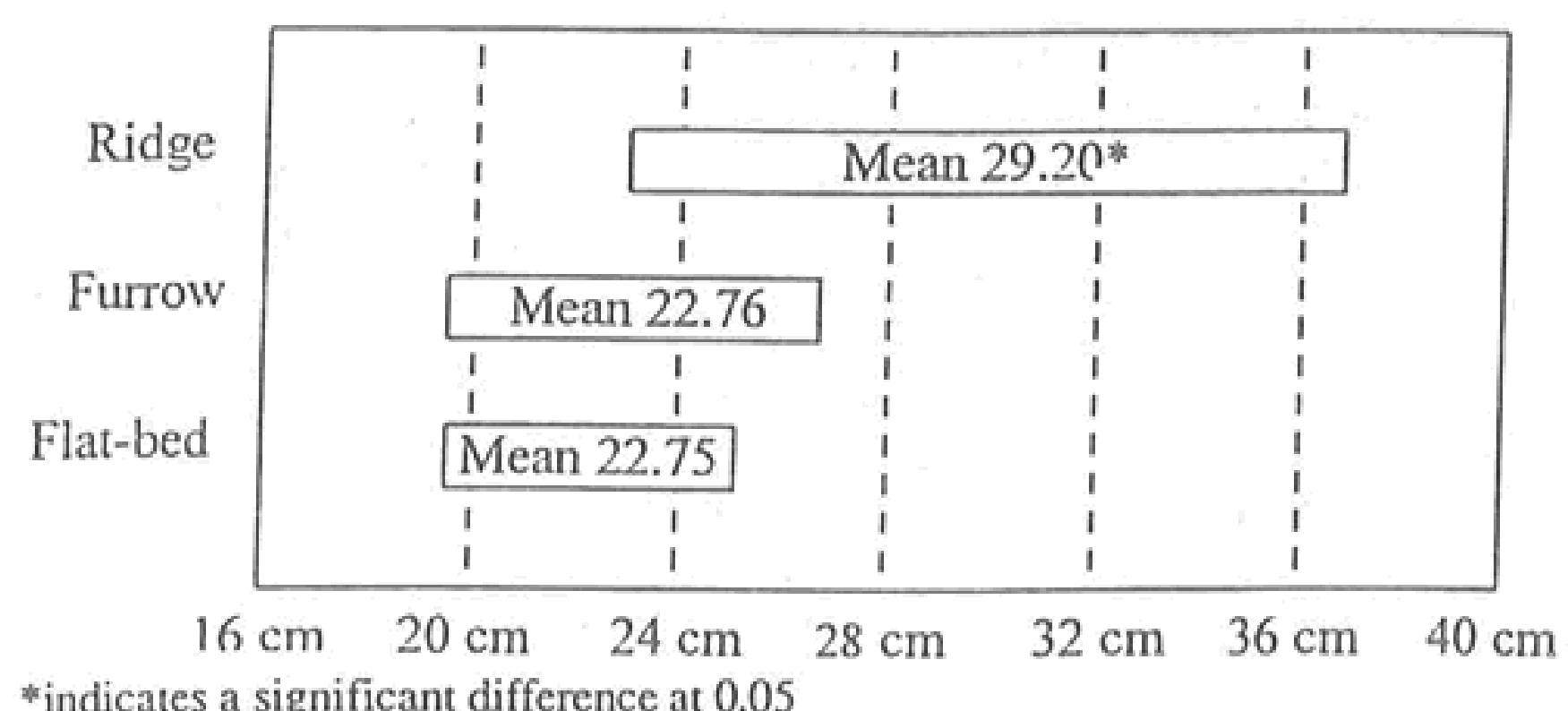

*indicates a significant difference at 0.05

Fig.1: Mean and range of root length of sampled sorghum plants for the three seedbed designs.

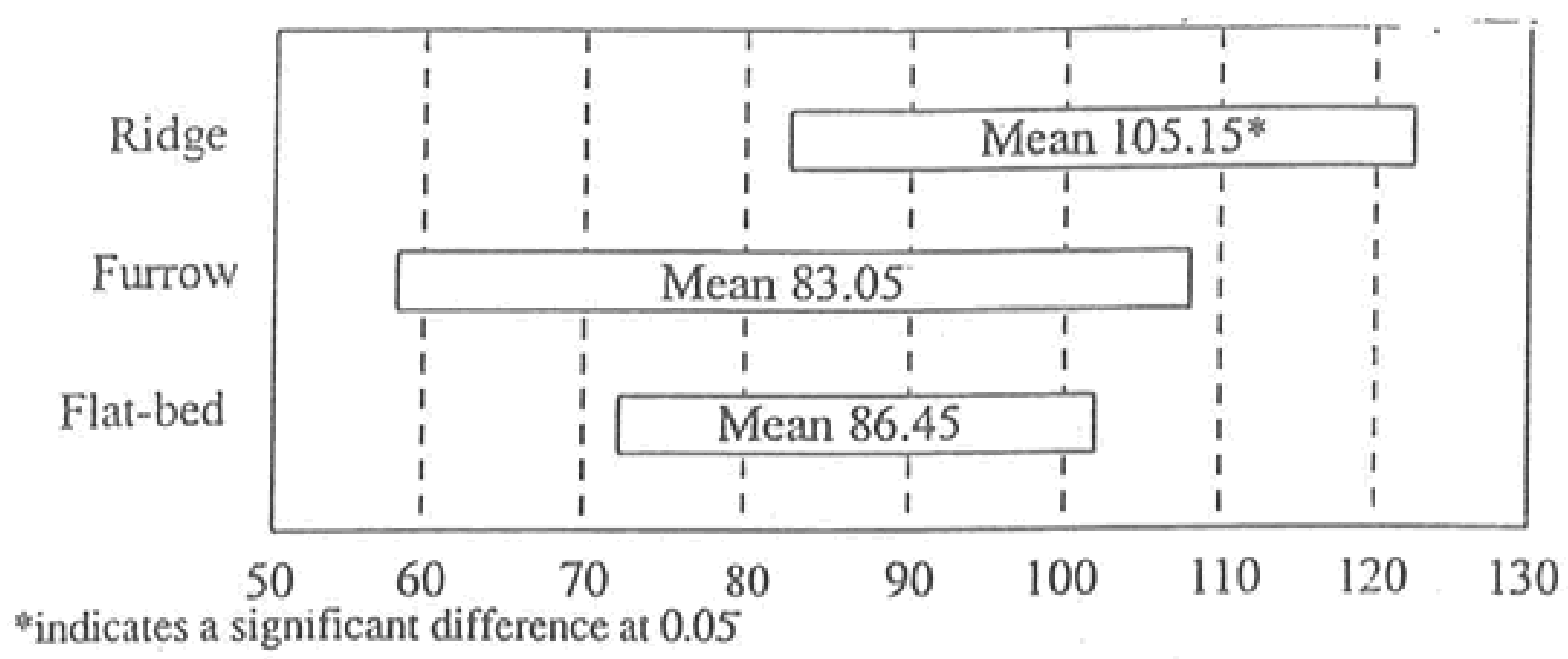

Fig. 2: Mean and range of plant height of sampled sorghum plants for the three seedbed designs.

Analysis of the data revealed a significant difference in the number of leaves produced between the sorghum plants sampled from the furrow and ridge treatment compared with those in the flat-bed treatment (Figure 3). Sampled plants from the flat-bed area had significantly fewer leaves than those from the furrow and ridge treatment areas (Figure 3). See Appendix Table 3 for statistical results. 
The data in Figure 4 shows the mean number of tillers per plant for each treatments. A significant difference was indicated between the sampled plants in the flat-bed and ridge treatment groups and those in the furrow treatment (Figure 4). The plants from the furrow area had significantly fewer mean tillers (1.9 tillers) compared with those from the flat-bed ( 4.3 tillers) and the ridge (4.6 tillers) treatments. There was no significant difference in number of tillers between the flat-bed and ridge treatment areas. It is interesting to note that though the mean height and root length for samples from the furrow treatment were significantly greater than samples from the flat-bed treatment, the sorghum plants sampled from the flat-bed treatment significantly out produced those in the furrow treatment relative to the number of tillers. See Appendix Table 2 for the statistical analysis.

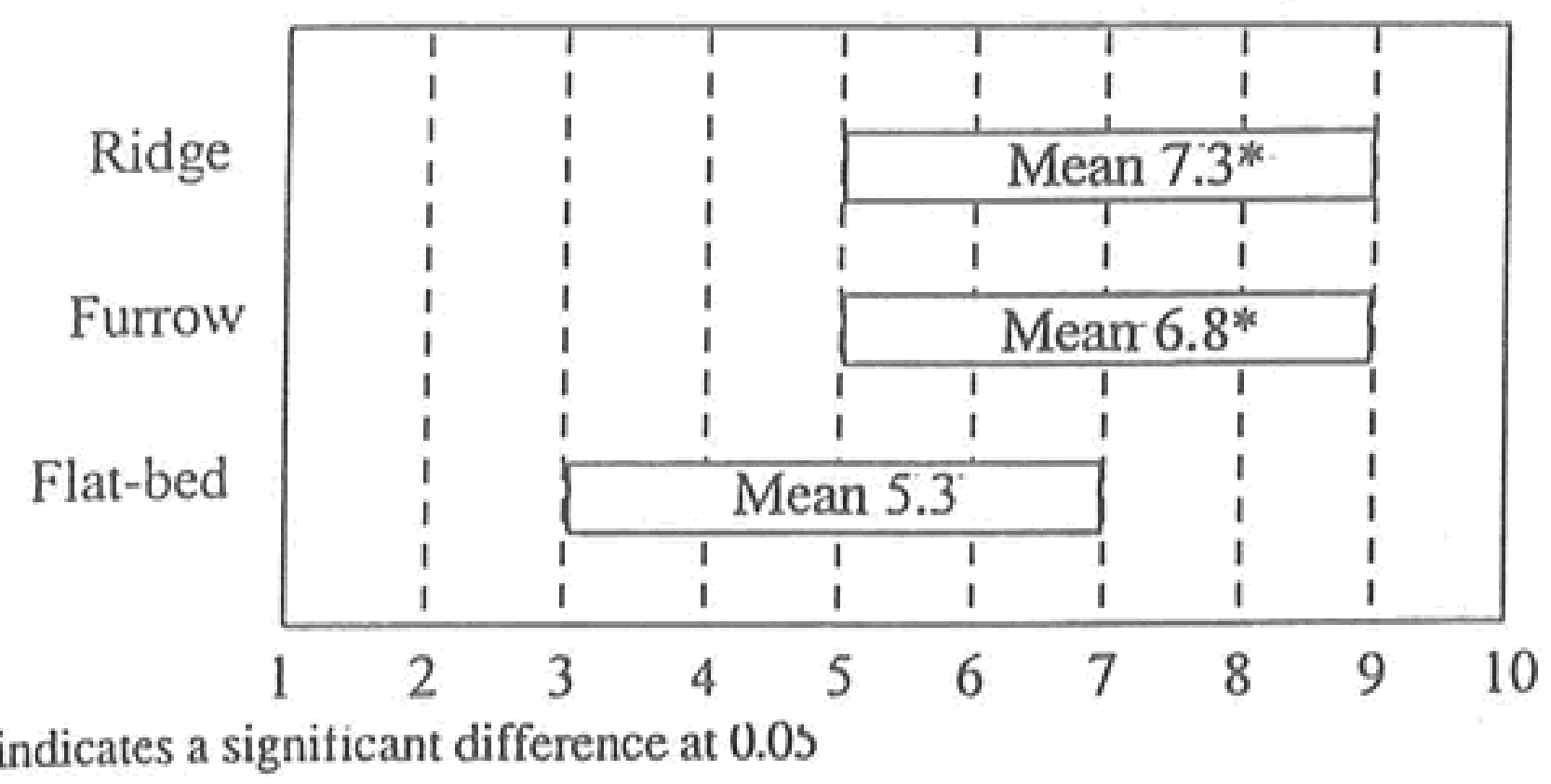

Fig. 3: Mean and range of number of leaves of sampled sorghum plants sampled for the three treatment designs. 


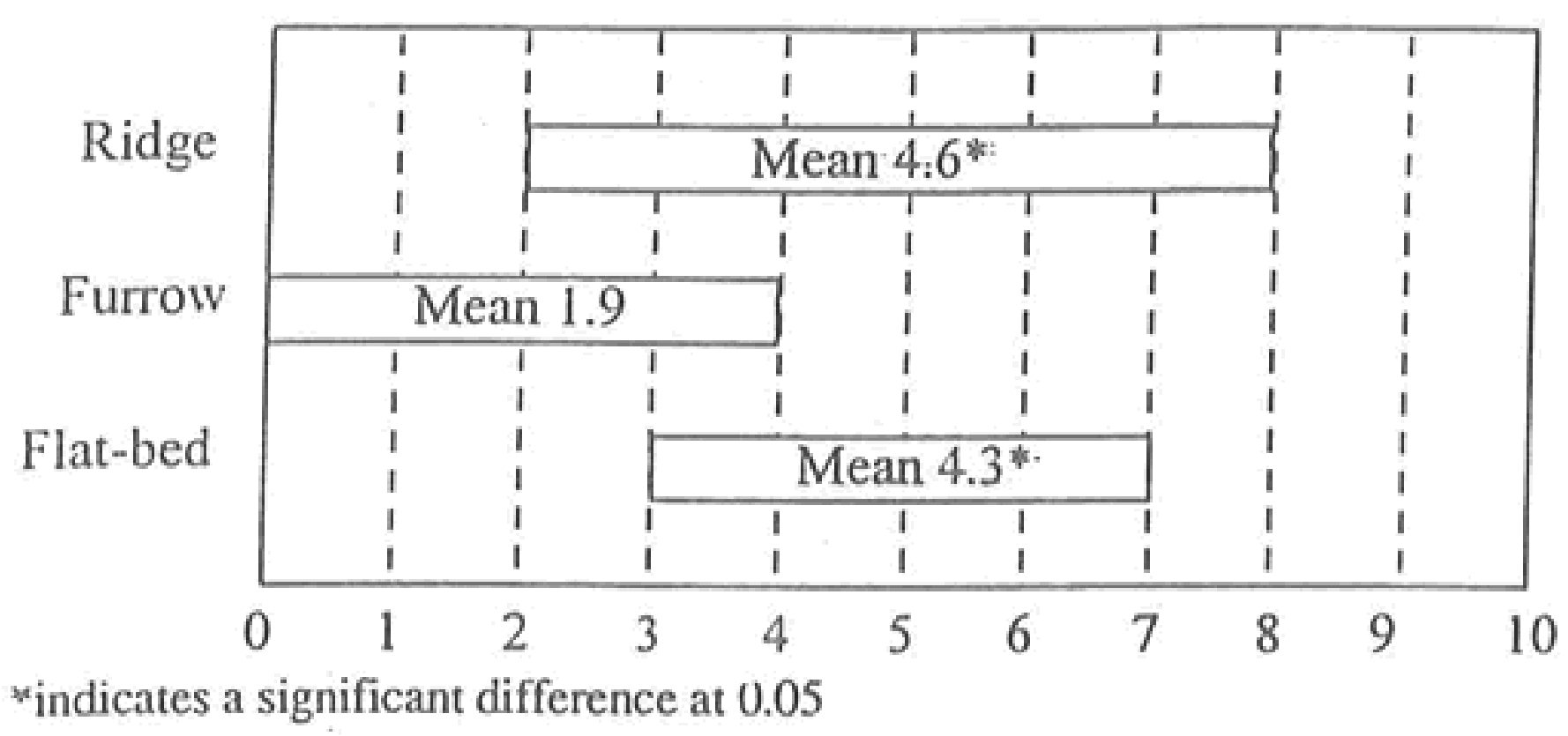

Fig. 4: Mean and range of number of tillers of sorghum plants sampled for the three treatment designs.

The mean fresh-weight for the plant samples from the three treatment areas are shown in Figure 5. A significant difference in freshweight was found between all three treatments. As indicated in Figure 5 , sorghum plants sampled from the ridge treatment produced a significantly higher mean fresh-weight than the other two treatments. The results indicate that the samples from the ridge treatment had greater than 1.5 times the mean fresh-weight of those from the flat-bed treatment area, and greater than 3.5 times that of the samples from the furrow treatment area. The mean fresh-weight for the samples from the flat-bed treatment was significantly higher than the mean fresh-weight for the furrow treatment. See Appendix Table 3 for statistical results.

When comparing the mean dry-weight for sampled sorghum plants from the three treatments, significant differences were again indicated between all three groups (Appendix Table 3). Coinciding with the results of the fresh-weight category, the mean dry-weight of samples from the ridge treatment was significantly higher than those from the other two treatments, and the mean dry-weight for samples from the flat-bed treatment were significantly greater than those from the furrow treatment (Figure 6). Sampled sorghum plants from the ridge treatment again had greater than 1.5 times the mean dry-weight of those from the flat-bed treatment, and greater than 5 times that of the samples from the furrow treatment area. 


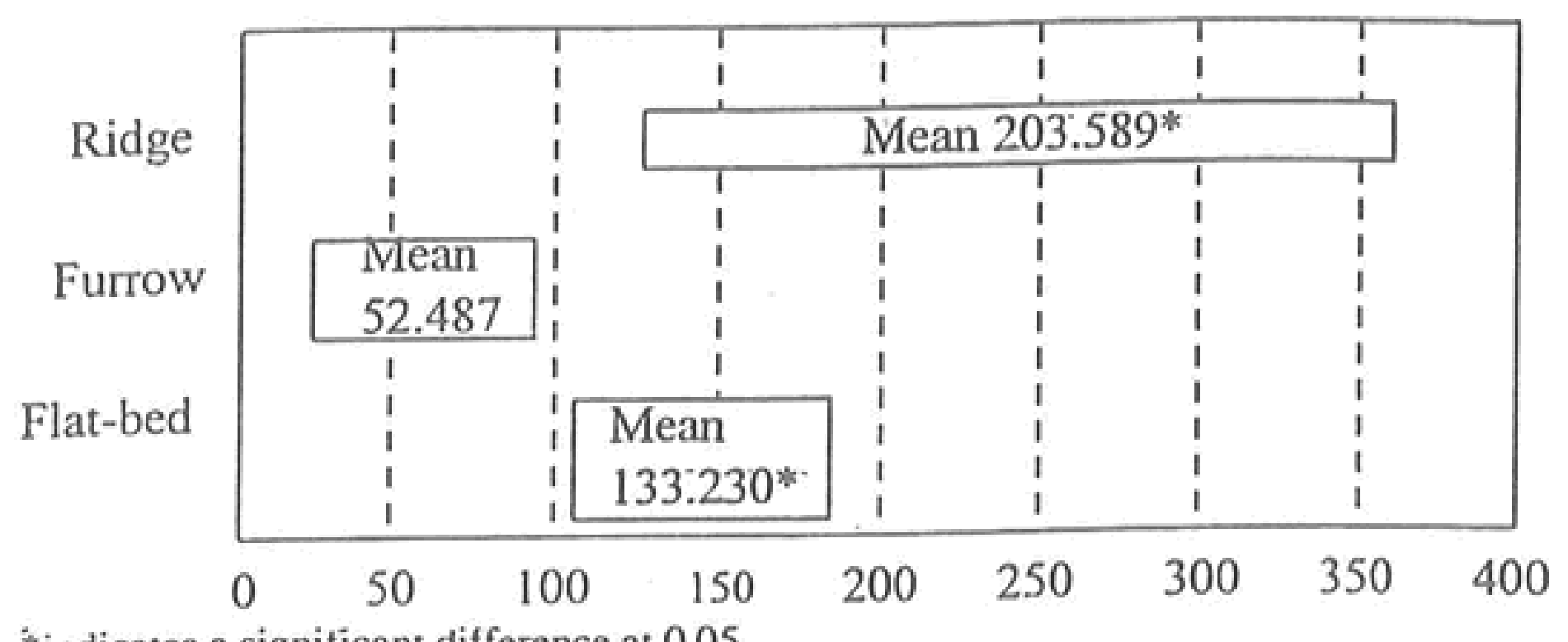

*indicates a significant difference at 0.05

Fig. 5: Mean and range of fresh weight of sorghum plants sampled for the three treatment designs.

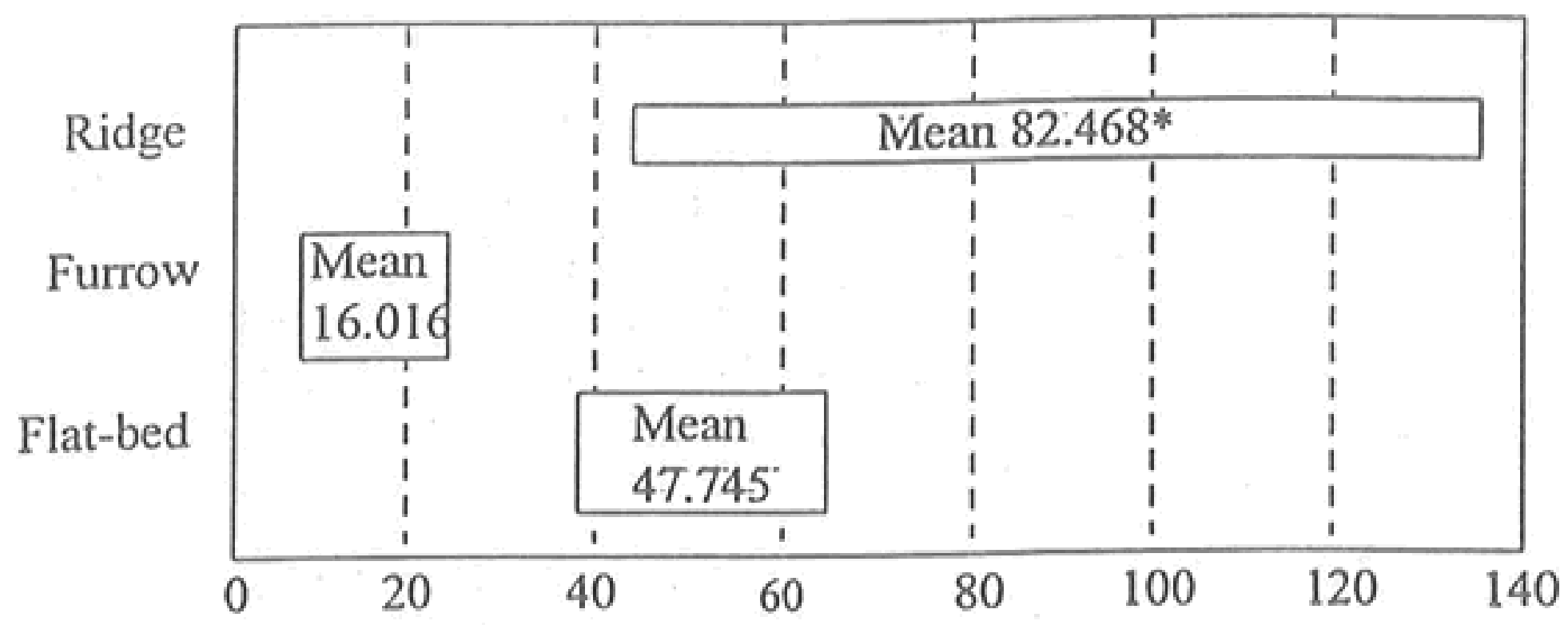

*indicates a significant difference at 0.05

Fig. 6: Mean and range of dry weights of sorghum plants sampled for the three treatment designs.

\section{ECONOMIC CONSIDERATION}

The key to any change in production practices by farmers is what will be the increase in product generated by the change and what does it cost to get the additional product. In this study the additional product is the increase in the fresh-weight of sorghum as a result of using the 
ridge and/or furrow planting system produced to be used as forage for livestock feed.

Several farmers in the Musanah area and one in the Rustaq area of the Sultanate of Oman were interviewed to determine the additional costs of using the ridge and furrow methods of seed bed preparation. The interviews revealed that it took approximately one more day of labor to prepare ridges for planting in a $225 \mathrm{~m}^{2}$ plot and about one half day more labor time for planting in the ridges than did the flat seedbed with broadcast planting. The farmers indicated it would not take as long to prepare the furrow seedbed but planting would take about the same as the ridge seedbed. The farmers indicated that they paid their labor 3 Oman Riyal (OR) a day.

The economic analysis is done on the basis of a $225 \mathrm{~m}^{2}$ plot. It is assumed that there are 10 sorghum plants per square meter and that the sorghum is cut $15 \mathrm{~cm}$ above the ground so the plants can produce a second and perhaps even a third cutting of fodder. These assumptions are based on the information concerning plot size planting and germination rates and harvesting techniques obtained in the farmer interviews.

The production data used in the economic evaluation are the plant weight from Appendix Table 1 and the plant fresh-weight from Appendix Table 3. To determine the fodder available from the sorghum plant, the values reported in Appendix Table 1 and 3 need to be adjusted to the weight harvested from the whole plant weight which is reported in Appendix Table 3. The following are the procedures used in the analysis.

$\Rightarrow$ The plant height in Appendix Table 1 is reduced by $15 \mathrm{~cm}$, (the assumed cutting height above the ground to allow for regrowth) to determine the amount of plant available for fodder.

$\Rightarrow$ The percent the harvested height of the whole plant height is next determined.

$\Rightarrow$ The whole plant fresh-weight is adjusted to fresh-weight of plant harvested for fodder by multiplying the whole plant fresh-weight by the percentage of the plant harvested. The result gives the plant fresh weight cut for fodder for the three seedbed systems. 
The gain in sorghum fodder available for livestock from switching to the ridge and furrow systems is estimated by subtracting the fresh-weight of fodder cut using the flat bed seeding from the freshweight of fodder cut obtained from the other two types of seedbeds.

The results of the analysis, shown in Table 1, indicate that the ridge method of seeding gives more fresh-weight of sorghum harvested than the flat method, 81.38 grams per plant. The furrow method of seeding did result in less fresh-weight sorghum harvested than the flat bed method.

Table 1. Determining harvested dry-weight of sorghum produced using three methods of seedbed preparation.

\begin{tabular}{lrrr}
\hline & \multicolumn{1}{c}{ Flat } & Ridge & Furrow \\
& & & \\
\hline Plant Height - cm & 86.450 & 105.150 & 83.050 \\
15 cm (cut level) & 71.450 & 90.150 & 68.050 \\
\% Original Plant Height (\% OPH) & 82.260 & 85.730 & 81.940 \\
Fresh-weight whole Plant (FWWP) & 113.230 & 203.589 & 52.870 \\
FWW x \% OPH = grams/plant & 93.142 & 174.536 & 43.240 \\
Increase in Fresh-weight over flat- & - & 81.384 & -49.802 \\
gram/plant & & & \\
\hline
\end{tabular}

Extending the results to a typical $225 \mathrm{~m}^{2}$ plot in the next step. This was done as follows:

$\Rightarrow$ The gain in fresh-weight harvested per plant was multiplied by the assumed planting and germinating rate per square meter. Ten plants per square meter is the rate use in this analysis based upon the farmer interviews.

$\Rightarrow$ The gain in fresh-weight harvested per square meter was multiplied by 225 square meters which is the assumed size of a typical sorghum plot in the two farming areas where the Omanie farmers were interviewed.

The results of the analysis to determine the total additional freshweight of sorghum fodder harvested is shown in Table 2. The ridge method of planting a $225 \mathrm{~m}^{2}$ plot with two cutting results in $266 \mathrm{k}$ more of fresh weight fodder harvested than produced when the flat-bed method of planting is used. 
Table 2. Total gain in dry-weight produced by ridge planting over flat bed planting per square meter and per 225 square meter plot

\begin{tabular}{|c|c|c|c|}
\hline & Gain per plant & $\begin{array}{l}10 \text { plant per } \\
\text { square meter }\end{array}$ & $\begin{array}{l}\text { Pants per } \\
225 \mathrm{~m}^{2}\end{array}$ \\
\hline $\begin{array}{l}1 \text { cutting } \\
2 \text { cutting }\end{array}$ & $\begin{array}{r}81.38 \mathrm{~g} \\
162.76 \mathrm{~g}\end{array}$ & $\begin{array}{r}813.80 \mathrm{~g} \\
1,627.60 \mathrm{~g}\end{array}$ & $\begin{array}{l}183.10 \mathrm{k} \\
366.20 \mathrm{k}\end{array}$ \\
\hline
\end{tabular}

The question to be asked is "Is the increased fodder production worth more than it costs to produce it?" The additional cost of the ridge method of planting was estimated to be one day of additional labor for preparing the seedbed ridges and one half day additional time for proper planting in the ridges. If the labor costs O.R. 3 per day, the added cost is:

$$
\begin{array}{lll}
\text { 1 day ridge preparation } & \text { O.R. } & 3.00 \\
\text { _day planting } & \text { O.R. } & 1.500 \\
\text { Total } & \text { O.R. } & 4.500
\end{array}
$$

The difficult question is what is the additional sorghum fodder worth? The producer interviews revealed that the farmers will sell the sorghum standing to someone that will then harvest it. The price for the plot of unharvested sorghum is determined by the size of the plot and the amount (size] of the sorghum. The more sorghum in the plot, the greater the value.

The price of sorghum fodder was recently obtained from the Seeb souq. The prevailing price was 100 baisa for 2 kilos. Using the market price, the value of the additional sorghum fodder is estimated to be O.R. 9 (183 k x O.R. 050) per cutting or O.R. 18 for two cuttings.

Given the price of O.R. 0.050 per kilo of sorghum fodder, it would be profitable for the farmer to plant his sorghum in ridges. The additional cost was estimated to be O.R. 4.500 and the exported additional return was estimated to be O.R. 18.000. The return over cost is O.R. 13.500.

If the farmer feeds the sorghum fodder to his own animals he will have 87 percent more fodder. The increased fodder would allow the farmer to feed more animals. 


\section{SUMMARY}

As previous research indicated that the seedbed preparation may have a profound impact on the seedbed environment and hence the successful production of the forage crop, the objective of this study was to compare the effects of three seedbed designs on the production of sorghum under the harsh-arid conditions found within the Sultanate. All other factors being equal (water, sunlight, nutrients, insecticide, etc.), the ridge design produced more sorghum forage-material than the other two techniques, and performed significantly greater in some respects. The ridge design produced significantly higher results in the categories of mean root length, plant height, fresh-weight and dryweight compared with both the flatbed and furrow tillage methods. Sorghum samples from the ridge treatment also produced significantly more leaves than samples from the flat-bed treatment, and significantly more tillers than samples from the furrow treatment.

Though surpassed by samples from the ridge design, sorghum samples from the flat-bed design significantly out performed samples from the furrow design relative to the number of plant tillers, freshweight and dry-weight. In contrast, sorghum samples from the furrow design outperformed samples from the flat-bed design relative to the number of leaves.

Appendix Table 1. Statistical analysis of root length and plant height

\begin{tabular}{|c|c|c|c|c|c|}
\hline & Mean & $\begin{array}{l}\text { Standard } \\
\text { Deviation }\end{array}$ & $\overline{\text { DF }}$ & $\begin{array}{l}\overline{\mathrm{F}} \\
\text { Value }\end{array}$ & $\begin{array}{l}\text { Value } \\
\text { Valu }\end{array}$ \\
\hline \multicolumn{6}{|c|}{ Root Length $(\mathrm{cm})$} \\
\hline Ridge & $* 29.20$ & 4.450 & & & \\
\hline Furrow & 22.76 & 2.174 & & & \\
\hline \multirow[t]{2}{*}{ Flat } & 22.75 & 1.674 & & & \\
\hline & & & 59 & 30.4 & $<0.001$ \\
\hline \multicolumn{6}{|c|}{ Plant Height $(\mathrm{cm})$} \\
\hline Ridge & $* 105.15$ & 9.021 & & & \\
\hline Furrow & 83.05 & 17.411 & & & \\
\hline \multirow[t]{2}{*}{ Flat } & 86.45 & 8.818 & & & \\
\hline & & & 59 & 18.3 & $<0.001$ \\
\hline
\end{tabular}

*Indicates a significant difference at 0.05 . 
Appendix Table 2. Statistical analysis of number of leaves and tillers on sampled sorghum plants for the three treatment designs.

\begin{tabular}{||l|r|r|r|r|r||}
\hline \hline & Mean & $\begin{array}{l}\text { Standard } \\
\text { Deviation }\end{array}$ & DF & $\begin{array}{c}\text { F } \\
\text { Value }\end{array}$ & $\begin{array}{l}\text { P } \\
\text { Value }\end{array}$ \\
\hline \hline Number of Leaves \\
\hline Ridge & $* 7.3$ & 1.455 & & & \\
\hline Furrow & $* 6.8$ & 1.281 & & & \\
\hline Flat & 5.3 & 1.218 & & & \\
\hline \multicolumn{7}{||}{} & & 59 & 12.40 & $<0.001$ \\
\hline Number of Tillers \\
\hline Ridge & $* 4.6$ & 1.729 & & & \\
\hline Furrow & 1.9 & 1.410 & & & \\
\hline Flat & $* 4.3$ & 1.302 & & & \\
\hline & & & 59 & 19.69 & $<0.001$ \\
\hline
\end{tabular}

*Indicates a significant difference at 0.05

Appendix Table 3. Statistical analysis of fresh-weight and dry-weight of sampled sorghum plants for the three treatment designs.

\begin{tabular}{||l|r|l|l|l|l||}
\hline \hline & Mean & $\begin{array}{l}\text { Standard } \\
\text { Deviation }\end{array}$ & DF & $\begin{array}{l}\text { F } \\
\text { Value }\end{array}$ & $\begin{array}{l}\text { P } \\
\text { Value }\end{array}$ \\
\hline \hline Fresh-Weight (grams) \\
\hline Ridge & ${ }^{2} 203.589$ & 78.031 & & & \\
\hline Furrow & $* 52.487$ & 17.247 & & & \\
\hline Flat & $* 133.230$ & 24.696 & & & \\
\hline \multicolumn{7}{|l|}{} \\
\hline Dry-Weight (grams) & & 59 & 49.03 & $<0.001$ \\
\hline Ridge & $* 82.468$ & 29.249 & & & \\
\hline Furrow & $* 16.016$ & 5.027 & & & \\
\hline Flat & $* 47.748$ & 7.763 & & & \\
\hline & & & 59 & 70.43 & $<0.001$ \\
\hline
\end{tabular}

*Indicates a significant difference at 0.05

The economic analysis indicated that the value of the additional sorghum fodder produced was significantly greater than the additional costs of preparing the ridged seedbed. 


\section{REFERENCES}

Aina, P.O. 1982. Soil and crop responses to tillage and seedbed configuration. Proceedings of the $9^{\text {th }}$ Conference of the International Soil Tillage Research Organization, pp. 72-78.

Aina, P.O. 1979. Tillage, seedbed configuration and mulching: a preliminary report on effects on soil and crops. Ife Journal of Agriculture. 1:26-35.

Alyaeesh, Faisal, U.G. Bokhari \& Mahmood Al-Noori. 1988. Potentials of forage crops in Saudi Arabia. Arab Gulf Journal of Scientific Research. Agricultural. Biological. Science. B6(3):359367.

Anazodo, U.G. N., A. P. Onwualu and K.C. Watts. 1991. Evaluation of alternative tillage systems in the absence of herbicides for maize production in a Savannah loamy sand. Journal of Agricultural Engineering Research. 49:259-272.

Benjamin, J.G., C.H. Choi, R.M. Cruse, M.A. Elamin, D.C. Erbach and S. Mukhtar. 1992. Soil and corn response to tillage with paraplow. Transactions of the A.S.A.E. 35(5):1347-1354.

Bhatt, G.M. and L.E. Evans. 1977. A nondestructive technique for measuring seedling vigor in wheat. Canadian Journal of Plant Science. 57:983-985.

Baruchin, Dinar and Yaron. 1982. Alternative cropping systems and intensive irrigation under arid zone conditions. Agricultural Systems. 38:301-318

Daniello, F.J., R.R. Hieneman and J. Mulkey, Jr. 1982. Influence of seedbed configuration on growth, development, and yield in muskmelon. Journal of the American Society of Horticulture Science. 107(3):445-447.

Ezedinma, F.O.C. 1964. Effect of preparatory cultivation on the general performance and yield of cowpea. Nigerian Agricultural Journal. 1:12-25.

Jones, M.J. 1987. Plant population, rainfall and sorghum production in Botswana. 1. Results of experiment station trials. Experimental Agriculture. 23:335-347. 
Klepper, B., R.W. Rickman and D.E. Wilkins. 1989. Measuring wheat seedling response to tillage and seedling systems. Transactions of the A.S.A.E. 32(3):795-800.

Kowal, J. \& K. Stockinger. 1973. Usefulness of ridge cultivation in Nigerian agriculture. Journal of Soil and Water Construction. 28:136-137.

Lal, R. 1973. Effect of seedbed preparation and time of planting on maize (Zea mays) in western Nigeria. Nigerian Experimental Agriculture. 9:303-313.

Lowe, L.B. and S.K. Ries. 1972. Effects of environment on the relation between seed protein and seedling vigor in wheat. Canadian Journal of Plant Science. 52:157-164.

Pidgeon, J.D. 1982. Paraplow - A rational approach to soil management. Proceedings of the $9^{\text {th }}$ Conference of the International Soil Tillage Research Organization, ISTRO, Osijec, Yugoslavia, pp. 633-638.

Sahn, D.E. ed. 1989. Seasonal Variability in Third World Agriculture: The Consequences for Food Security. The John Hopkins University Press, Baltimore, M.D, U.S.A.

Seavoy, R.E. 1989. Famine in East Africa Food Production and Food Policies. Greenwood Press, Inc., Westport, CT., U.S.A.

Wannapee, P. 1982. Factors affecting the swing of planting seeds: land preparation and planting. Intsoy Service, University of Illinois, College of Agriculture, Urbana, Illinois. 22:102-106.

Younis, S.N.A. 1986. System approach to machinery selection (Saudi agriculture case). Arabian Gulf Journal of Scientific Research. 4(2):679-691. 